\title{
The time sequence of RNA and protein synthesis in cellular compartments following an acute dietary challenge with amino acid mixtures
}

\section{By W. H. WunNeR, Department of Biochemistry, University of Glasgow}

The absorption of amino acids from the alimentary tract during digestion following a meal which contains protein is a rapid process with a maximum rate of absorption within the Ist hour (Dawson \& Holdsworth, 1962; Chen, Rogers \& Harper, 1962). Most of the amino acids absorbed at this early time are apparently derived from the exogenous protein, due to the differences in rate of digestion of exogenous and endogenous protein in the gut (Nasset $\& J u, 1961$ ). Thus, appreciable quantities of exogenous amino acids are present in the distal duodenum and proximal jejunum and are absorbed from the small intestine before amino acids derived from the more slowly digested endogenous protein alter the amino acid composition of the intestinal contents. Consequently, in the interval between one meal and the next, the supply of amino acids from the intestine to the portal blood will fluctuate in both quantity and quality.

Free amino acids in portal blood are removed from circulation by the liver and incorporated into tissue protein in an extremely short time, a matter of minutes. The rate of incorporation of amino acids into cellular protein from portal blood is a function not only of the cellular rate of protein synthesis but also of the rate of penetration of the amino acids into the cell (Henriques, Henriques \& Neuberger, 1955). The net uptake is related to both the extracellular and intracellular concentrations of amino acids, a relationship which is not a simple and direct one, and depends on the efficiency of transport mechanisms for the individual amino acids (Christensen, I955). Nevertheless, Hanking \& Roberts (1965) have shown by incubating liver slices in a medium containing various amounts of phenylalanine or threonine that the amino acid incorporating activity of ribosomes isolated from the liver slices is sensitive to the extracellular concentration of these amino acids. These observations suggest that protein synthesis in the liver cell is acutely responsive to variations in intracellular levels of amino acids induced by primary alterations in the extracellular concentration of a single essential amino acid. In studying the pattern of absorption of individual amino acids from mixtures in the rat intestine in situ, Delhumeau, Velez Pratt \& Gitler (1962) found that modifications of the ratios of amino acids from equimolar mixtures to those in hydrolysates of egg albumin, casein or zein did not change the relative order of absorption of the individual amino acids (based on the percentage absorbed), but the total amount absorbed was markedly higher for the amino acids present in the simulated egg albumin hydrolysate. Furthermore, they observed nearly simultaneous absorption of all amino acids from the simulated egg albumin mixture. It therefore seems likely that the amino acid content of portal blood during intestinal protein digestion can influence the pattern appearing in the tissues and modify the efficiency of utilization of the amino acids by the cells. 
The pattern of amino acids available for protein synthesis in the cell is very difficult to assess in view of the likelihood that the cellular content of free amino acids may be structurally compartmentalized, that is, restricted to microsomes, nuclei, mitochondria or other morphological sites where protein synthesis is known to occur, and therefore is not functionally homogeneous with respect to protein synthesis (Kipnis, Reiss \& Helmreich, 1961). Nevertheless, the rate of protein synthesis apparently depends on the availability of free amino acids in the correct proportions necessary to meet the requirements of the cell for protein synthesis. The rate of amino acid incorporation into protein would appear to depend, also, on the very precise co-ordination, at the molecular level, of structural components engaged in protein synthesis (Campbell, r 966). Nutritional studies of the effect of protein intake on body protein metabolism have now advanced to the point at which it is possible to examine the impact of amino acid supply on these subcellular components. Let us first consider the effect on polysomes.

In previous studies, we have demonstrated that the polysomes in the liver cell are sensitive to amino acid supply (Fleck, Shepherd \& Munro, 1965; Wunner, Bell \& Munro, 1966). Polysomes of the hepatic cell are formed by ribosomes attached to strands of messenger RNA coding for the amino acid sequences of protein, and are the sites of polypeptide chain formation. As it is possible that amino acid availability may alter the rate of protein synthesis and thus the speed of attachment and detachment of ribosomes on the messenger strand (Noll, Staehelin \& Wettstein, 1963), the absence of one amino acid required in the peptide sequence could alter polysome stability (Villa-Trevino, Farber, Staehelin, Wettstein \& Noll, 1964). When rats are fed with an amino acid mixture lacking tryptophan, the polysomes undergo some alteration in their structural integrity to yield a greater proportion of the small polyribosomes (Wunner et al. 1966 ). This shift in polysome profile in response to the tryptophan-free diet suggests polysome breakdown, a phenomenon which can be reversed when tryptophan is added to the diet. In this paper, I would like to discuss some preliminary evidence for a sequence of events involved in protein synthesis at the cellular level following an acute dietary challenge with amino acid mixtures. These studies were designed to investigate nutrient utilization in relation to patterns of protein feeding.

\section{Methods}

Treatment of rats. Male albino rats weighing $150 \mathrm{~g}$ were starved for $\mathrm{i} 8 \mathrm{~h}$ and then fed, by stomach-tube, with a mixture of amino acids prepared to simulate the composition of egg albumin (Wunner et al. 1966 ). Each rat received $\mathrm{I} \cdot 2 \mathrm{~g}$ of amino acids per $3 \mathrm{ml}$ of the mixture in a single feeding and was deprived of drinking water during the period of absorption which followed. On the occasions of refeeding with another $3 \mathrm{ml}$ of the mixture, the stomach was not aspirated before refeeding. Throughout these studies, two amino acid mixtures were used. The nutritionally complete amino acid mixture served as control to the effect of feeding with a similar amino acid mixture with tryptophan omitted. The rats were killed by decapitation at various times after single and double feedings, and livers were quickly removed and chilled 
in tris- $\mathrm{HCl}$ buffer, $\mathrm{pH} 7 \cdot 6$, containing $0.25 \mathrm{M}$-sucrose, $25 \mathrm{mM}-\mathrm{KCl}$ and $5 \mathrm{mM}-\mathrm{MgCl}_{2}$ for the preparation of polysomes as described previously (Wunner et al. 1966).

Isotopic labelling. Rats were injected intraperitoneally with $\left[5^{-3} \mathrm{H}\right]$ orotic acid ( $200 \mu \mathrm{c} / \mathrm{rat}$ ) at the time of feeding with amino acid mixtures. The uptake of radioactivity into the RNA of the liver polysome fraction was measured by suspending the polysome pellet in $0.6 \mathrm{ml} \mathrm{H} \mathrm{H}_{2} \mathrm{O}$ and treating the suspension with $\mathrm{I} \%$ sodium dodecyl sulphate (SDS) at $37^{\circ}$ for $5 \mathrm{~min}$. To a sample $\left(5^{\circ} \mu 1\right)$ of the SDS-extracted RNA $+0.95 \mathrm{ml} \mathrm{H}_{2} \mathrm{O}, 8 \mathrm{ml}$ Scintstant NE 572 in dioxan, scintillation grade (Nuclear Enterprises Ltd, Edinburgh), was added in glass liquid-scintillation vials. The samples were counted in a Packard Tricarb liquid-scintillation counter and corrections were made for background and for counting efficiency by the channels-ratio procedure. The SDS-extracted RNA plus $0.2 \%$ solution of bovine serum albumin in $\mathrm{I} \mathrm{ml}$ was precipitated with an equal volume of $0.4 \mathrm{~N}-\mathrm{HClO}_{4}$ and estimated by the ultraviolet-absorption method of Fleck \& Begg (1965).

Electron microscopy. Portions of the median lobe of the liver were taken for electron microscopy. The tissues were chopped into small pieces in ice-cold $2 \%$ osmium tetroxide in phosphate buffer, $\mathrm{pH} 7 \% 4$, and fixed for $40 \mathrm{~min}$ at $4^{\circ}$. The fixed tissues were then dehydrated through a graded series of solutions increasing from $50 \%$ to absolute ethanol and embedded in Epon following on different occasions the methods of Luft (1961) and Lockwood (1964). Thin sections were cut on an LKB ultratome and stained with uranyl acetate for $\mathrm{I} h$ followed by lead hydroxide (Watson, I958) for $10 \mathrm{~min}$. Specimens were viewed in a Siemens Elmiskop I electron microscope at a magnification $\times 10000$.

\section{Results and discussion}

Liver polysome profiles. Isolated liver polysomes prepared by the method of Wettstein, Staehelin \& Noll ( 1963 ) have been analysed on sucrose-density gradients following the administration of tryptophan-free and complete amino acid mixtures (Fleck et al. 1965; Wunner et al. 1966). The method of analysing the resulting polysome profiles provides an estimate of the distribution of various ribosomal aggregate sizes in the isolated polysome fraction. Normally, it is possible to resolve clearly the smaller polyribosomes (oligosomes) in the region of the monomer to hexamer in the total polysome profile. These show reasonably symmetrical peaks of material absorbing at $260 \mathrm{~nm}$. The heavier polyribosomes ( $>6$ ribosomes) constitute a larger proportion of the total profile and extend under one broad peak to the end of the tracing. The area under the tracing represented by each component is expressed as a percentage of the total area under the entire polysome tracing (Webb, Blobel \& Potter, I964).

The liver polysome profile $2 \mathrm{~h}$ after feeding with the amino acid mixture lacking tryptophan characteristically has a high proportion of oligosomes compared to that obtained from rats fed with a complete mixture (Wunner et al. 1966). The dimer component accounts for nearly half of the increased amount of oligosomes in the 'tryptophan-deficient' rats. Since the change in the polysome profile is most marked in the accumulation of the dimers, a measure of this component relative to the total 
polysome profile has been taken to indicate the degree of the response in the liver polysomes to the dietary challenge with amino acid mixtures.

The duration of the effect of amino acid feeding is illustrated in Fig. I using the percentage of dimers in the polysome profile as a measure of the difference in profiles. Rats fed with the tryptophan-free amino acid mixture over a $7 \mathrm{~h}$ period showed a maximum response at 2 and $3 \mathrm{~h}$ which decreased thereafter in the remaining $4 \mathrm{~h}$ of the postabsorptive period. This would suggest, in the case of the 'tryptophan-deficient' group, the participation of an adaptation process.

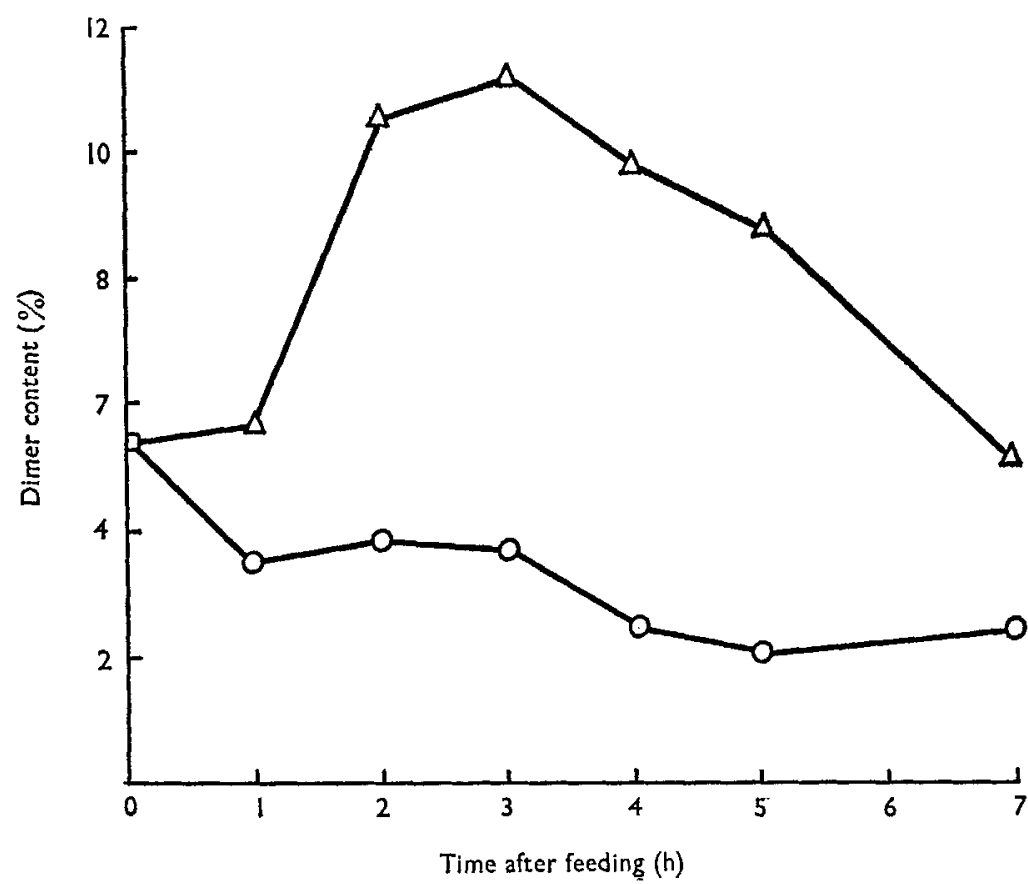

Fig, I. Percentage of dimers in liver polysome profiles during a $7 \mathrm{~h}$ postabsorptive period. Rats starved for $\mathrm{I} 8 \mathrm{~h}(\square)$ were fed either with a nutritionally complete amino acid mixture $(\mathrm{O}-\mathrm{O}-\mathrm{O})$ or with a similar mixture lacking tryptophan $(\triangle-\triangle)$. Liver polysome fractions were isolated and analysed on sucrose-density gradients for the size distribution of polyribosomes. The percentage of dimers to total polyribosomes of the polysome profile was used as a measure of polysome profile change.

Electron microscopy of liver thin sections. Livers of rats fed with the complete and tryptophan-free amino acid mixtures were taken at the $2 \mathrm{~h}$ and $7 \mathrm{~h}$ intervals after feeding to examine morphological detail. At the ultrastructure level, two types of polyribosomes are distinguished, a membrane-bound form and membrane-free form. The morphological appearance of polyribosomes in the hepatic cell of rats fed the complete amino acid mixture is well organized after $2 \mathrm{~h}$ in both membranebound (AR) and free (FP) forms (Pl. I). Ribosomes are attached to the thin membrane of the rough-surfaced lamellar cisternae of the endoplasmic reticulum (Pl. 2a) which is an easily recognized system of longitudinal channels arranged roughly in parallel. It has been suggested, from studies on synthesis, intracellular transport, 
storage and discharge of secretory proteins in the pancreatic exocrine cell, that the ribosomes in the form of polysomes attached to the endoplasmic reticulum synthesize proteins which are transferred to the inside of the membrane if they are to be secreted by the cell (Caro \& Palade, I964). Free polysomes are visible in the cytoplasmic matrix with no apparent attachment to membrane (Pl. $2 b$ ). They take the shape of spirals, rosettes and straight rows of ribosomes which are presumably held together by a strand of messenger RNA (Benedetti, Bont \& Bloemendal, 1966). It is possible that these morphologically distinct polysomes synthesize another type of protein for liver function. The spiral configuration suggests that these may be segments of a helical arrangement. A model for the helical structure of free polysomes has been discussed by Shelton \& Kuff (1966). Many free ribosomes, obviously not in polysome formation, can be seen scattered throughout the cytoplasm.

The morphological appearance of these cytoplasmic components $2 \mathrm{~h}$ after feeding with the tryptophan-free amino acid mixture is considerably altered (P1. 3). Much of the general cytoplasmic organization and continuity is lost. The endoplasmic reticulum appears fragmented and expanded to form many rather large membranelimited vacuoles (Pl. $3 a$ and $c$ ). Areas of highly organized free polysomes are no longer detectable. However, comparable regions in the cytoplasm surrounded by mitochondria can be located in which considerably more free ribosomes and small clusters of ribosomes are dispersed (Pl. $3^{b}$ and $c$ ). In general, the number of free ribosomes appears to be vastly increased.

The fine structural characteristics in the cytoplasmic matrix of the liver cell at $7 \mathrm{~h}$ following the administration of the tryptophan-free amino acid mixture compared to those at $2 \mathrm{~h}$ appear to have a higher degree of order (P1. $4 a)$. The basic features of the endoplasmic reticulum and free polysomes found in the cell at $2 \mathrm{~h}$ after feeding with the complete mixture are reappearing at $7 \mathrm{~h}$ in the tryptophanfree group which suggests a tendency to adaptation. There is an apparent reduction in the amount of expanded endoplasmic reticulum and a more definite arrangement of ribosome-studded lamellar cisternae. Also, there is more indication that spirals of free polysomes are reappearing in zones of the cytoplasmic matrix ( $\mathrm{Pl} .4 b)$. In fact, it is difficult to differentiate the general pattern of structure in thin sections between the groups of 'tryprophan-free' (Pl. $4 b$ ) and 'complete'-fed rats (PI. $4 c)$ after 7 h.

Some differences in the general characteristics of the nuclei between the dietary groups are worth mentioning, though the structural forms are less distinctive. Nuclei are very heterogeneously stained in the thin sections of liver from rats fed with the complete mixture showing regions of fine-textured chromatin around the more densely stained nucleoli and also at the periphery immediately under the nuclear envelope (P1. I). The nuclei of livers from rats fed with the tryptophan-free mixture are at $2 \mathrm{~h}$ more homogeneously stained ( $\left.\mathrm{Pl} .3^{a}\right)$; whereas at $7 \mathrm{~h}$ the nucleoplasm is again heterogeneously stained (P1. $4 a$ ), with a tendency for more of the densely stained RNA and nucleoprotein to occur at the periphery. The possible significance of this observation will be discussed later.

The combined results of examining ultrastructure of the liver cell and profiles of liver polysomes emphasize the variation in cellular continuity, particularly of the 
components engaged in protein synthesis, during the $7 \mathrm{~h}$ interval after feeding amino acid mixtures. As mentioned earlier, the initial pattern of amino acids absorbed from the upper portion of the intestine more accurately reflects the amino acid content of the ingested protein or amino acid mixture, whereas after $7 \mathrm{~h}$ this pattern may be altered by the contribution of amino acids from the more slowly digested endogenous protein. Thus, the variation in liver polysome response during the $7 \mathrm{~h}$ period may reflect the changing amino acid pattern as amino acids are absorbed further along the alimentary tract. However, this cannot be readily demonstrated, since the intracellular amino acids available for protein synthesis are likely to be compartmentalized, making a precise measurement of individual amino acids in the cell very difficult to carry out and evaluate. Alternatively, it is possible to alter the pattern of available amino acids in the dietary mixture and observe the cellular response to the impact of the new amino acid supply, assuming that the initially absorbed amino acids reflect the composition of the dietary mixture at the cellular level. The following experiments show the rapidity with which the cell recognises the supplement of tryptophan in the complete amino acid mixture after feeding with the tryptophan-free mixture.

Polysome profiles in response to repetitive feeding. In these experiments, the effect of refeeding the complete amino acid mixture to rats previously fed with the tryptophan-free mixture was compared to refeeding similar pre-fed rats with the incomplete mixture. Five different dietary treatments were used (A-E). Three $(A, B$ and $C$ ) involved an initial feeding with the tryptophan-free amino acid mixture and two ( $D$ and $E$ ) with the complete mixture. After $2 \mathrm{~h}$, rats receiving treatment $\mathrm{B}$ were re-fed with the incomplete mixture, and those receiving treatment $\mathrm{C}$ and $\mathrm{E}$ were re-fed with the complete mixture. Rats on treatments $A$ and $D$ were fed only once and served as controls to the effects of refeeding with the respective amino acid mixtures. The controls were killed at the time of refeeding, and the remaining rats at intervals of $0.5,2$ and $3 \mathrm{~h}$ after the second feeding. The results of an analysis of the liver polysome profiles are shown in Fig. 2.

Again, the shift in the polysome profile of rats initially fed with the tryptophanfree mixture is characterized by the increased dimer content after $2 \mathrm{~h}$. Within 30 min after refeeding with the complete amino acid mixture, however, the polysome profile is reversed and looks very similar to the profile obtained from livers of rats fed with the complete mixture alone, and remains that way for up to $3 \mathrm{~h}$ after the second feeding. At the same time, refeeding the 'tryptophan-deficient' rats with the tryptophan-free mixture maintains the polysome profile with a high percentage of dimers.

Ribosomal RNA synthesis following acute dietary challenge with amino acids. One of the questions that arises with regard to the nature of polysome formation in response to the supply of tryptophan in the diet, is whether or not the free ribosomes found in the cytoplasm mediate the response, that is, recycle into functional polysomes. Alternatively, polysome formation may be regulated entirely in the nucleus, the site of messenger RNA and ribosomal RNA synthesis and ribosome formation, whereby the stimulus for polysome formation initiates an increased rate of RNA synthesis or 


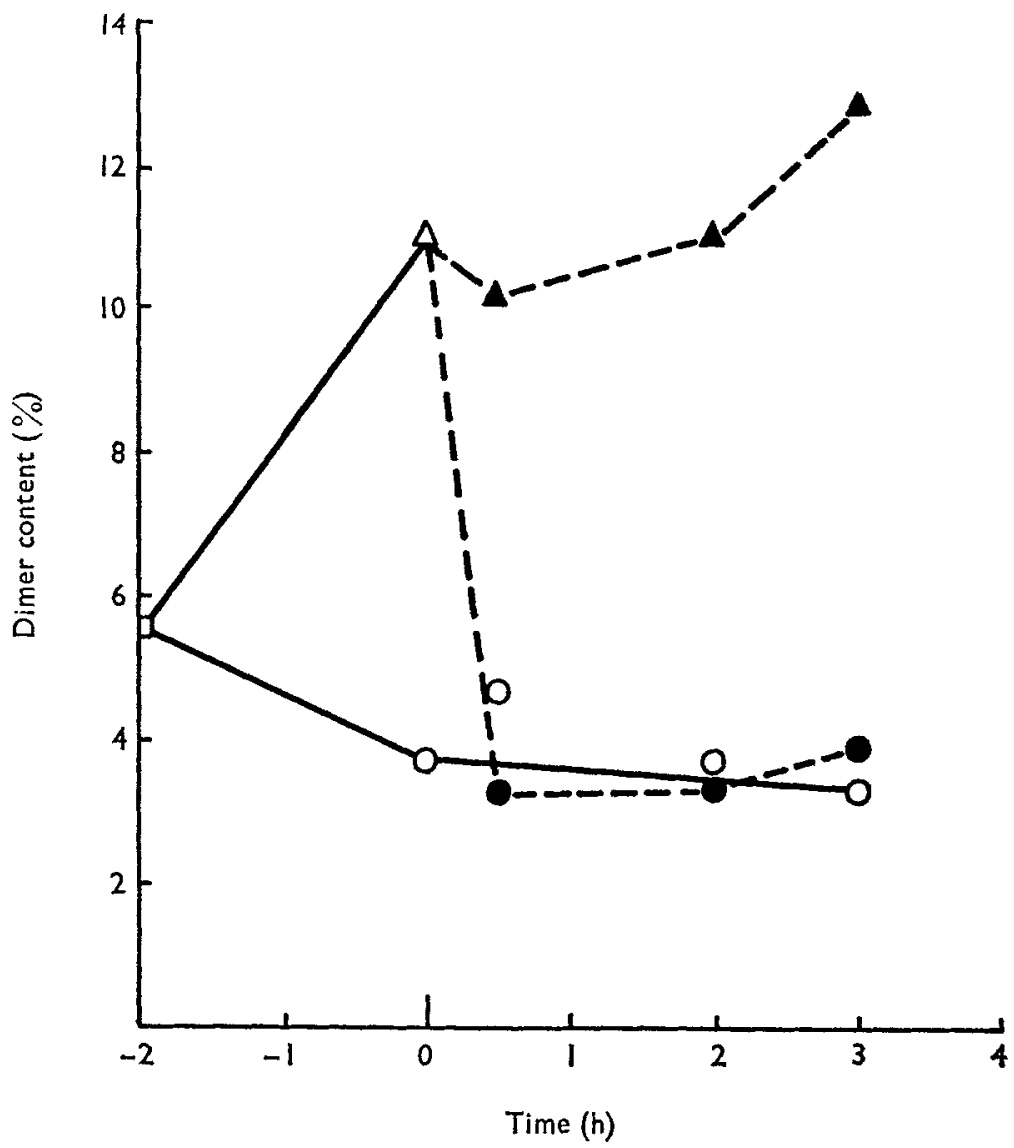

Fig. 2. Percentage of dimers in liver polysome profiles in response to single and double feedings (dietary treatments A-E) with amino acid mixtures. Rats starved for $\mathrm{I} 8 \mathrm{~h}(\square)$ were fed with a tryptophanfree amino acid mixture (A), $\square--\triangle$, or a complete amino acid mixture (D), $\square-\square-O$, for $2 \mathrm{~h}$. Rats fed first with the tryptophan-free mixture were then re-fed with the tryptophan-free mixture (B), $\mathbf{A}--\mathbf{A}$, or the complete amino acid mixture (C), - - - , and rats fed first with the complete mixture were re-fed with the complete amino acid mixture $(\mathrm{E}), \mathrm{O}-\mathrm{O}-\mathrm{O}$. Animals were killed at $0.5,2$ and $3 \mathrm{~h}$ intervals after refeeding, and liver polysome fractions were isolated and analysed on sucrose-density gradients. The percentage of dimers to total polyribosomes of the profile was used as a measure of polysome profile change.

release of precursors to polyribosomes or both. There is a tremendous gap in our knowledge, at present, of the concerted mechanisms between the catabolic and synthetic processes that determine the cellular concentration of these essential components of the protein-synthesizing apparatus. We are just beginning to make measurement of the kinetics of synthesis of rat liver cytoplasmic polyribosomes in response to the nutritional changes.

The results of some preliminary experiments using dietary treatments $\mathrm{A}, \mathrm{B}$ and $\mathrm{C}$ and injecting $\left[{ }^{3} \mathrm{H}\right]$ orotic acid $(200 \mu \mathrm{c} /$ rat $)$ at the time of the first feeding for RNA labelling, show that the specific activity of RNA in the polysome fraction is increased at $0.5,2$ and $3 \mathrm{~h}$ intervals after feeding the complete amino acid mixture to rats which were previously fed with the amino acid mixture lacking tryptophan (Fig. 3, $26(2) 2$ 


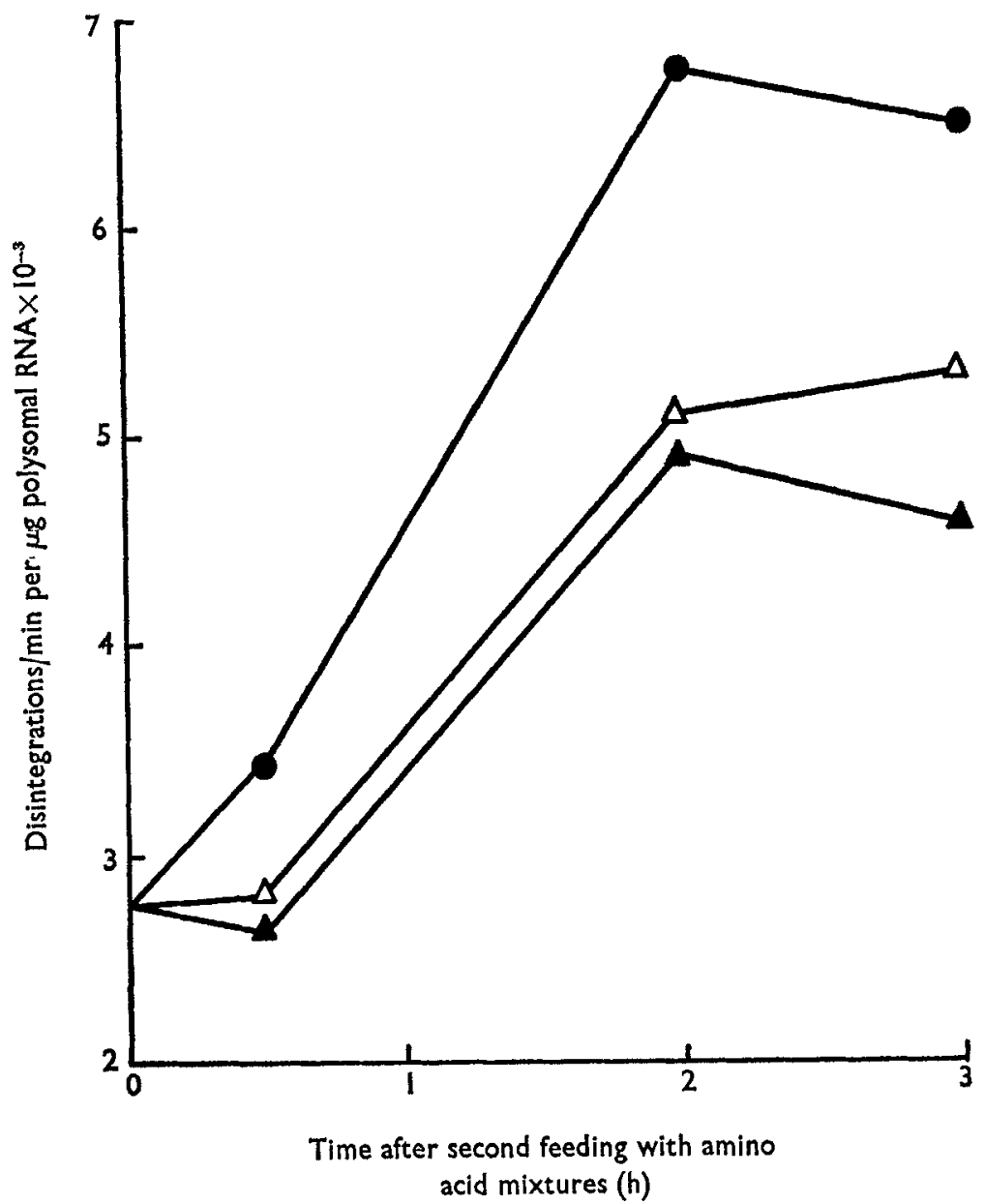

Fig. 3. The incorporation of $\left[{ }^{3} \mathrm{H}\right]$ orotic acid into polysomal RNA in response to feeding with amino acid mixtures. Rats were initially fed with the amino acid mixtures. Rats initially fed with the amino acid mixture lacking tryprophan (dietary treatments $A, B$ and $C$ ) were injected at the time of first feeding

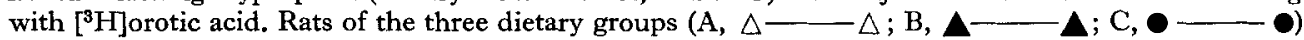
were killed at $0.5,2$ and $3 \mathrm{~h}$ after the time of second feeding, liver polysomes were prepared, and RNA was extracted from the polysome fractions by treatment with $1 \%$ sodium dodecyl sulphate in water.

group C). This fraction contains messenger, ribosomal and traces of transfer RNA. It is estimated that at the time of refeeding, $2 \mathrm{~h}$ after the initial feeding and injection of $\left[{ }^{3} \mathrm{H}\right]$ orotic acid, only $15 \%$ of the label is bound in total liver RNA. This implies that $85 \%$ of the label is in the free form when tryptophan is supplied with the complete amino acid mixture. The interpretation of the increased $\left[{ }^{3} \mathrm{H}\right]$ orotic acid incorporation into liver polysomes must take into account the possible re-utilization of isotope in the form of free cytoplasmic ribosomes, even though it may be assumed negligible owing to the dilution effect of the large cytoplasmic pool of free ribosomes. At the same time, the release of new polysome precursors, messenger RNA and ribosomal RNA, from the nucleus stimulated by the complete amino acid mixture, would account for much of the increased specific activity of RNA in the polysome fraction. 


\section{Conclusion}

To summarize, feeding rats with an amino acid mixture lacking tryptophan increased the number of small polyribosomes in the isolated liver polysome fraction within the first $3 \mathrm{~h}$ of the postabsorptive period. However, over the remaining $4 \mathrm{~h}$ of the period studied, the polysome profile was progressively changed to resemble the profile obtained after giving the complete amino acid mixture. The appearance of the cell ultrastructure examined by electron microscopy was in agreement with the change in polysome profiles. When oligosome accumulation was maximal, that is, $2 \mathrm{~h}$ after feeding with the tryptophan-free amino acid mixture, the morphological appearance of the endoplasmic reticulum and cytoplasmic polysome system was different from that of control rats fed the complete amino acid mixture. The organization of the lamellar cisternae was disrupted, and there were fewer free polysomes with the spiral configuration. By $7 \mathrm{~h}$ after feeding with the incomplete mixture, the cellular structure was very similar to that of the control rats.

It is possible that the restoration of liver polysome profiles and morphological detail of the hepatic cell at the end of the $7 \mathrm{~h}$ postabsorptive period studied reflects the gradual supply of tryptophan to the cell from endogenous sources, for example intestinal protein secretions and labile tissue protein (Twombly \& Meyer, I96r). This is supported by the observation that the polysome pattern from the tryptophanfree rats was restored to that of the control rats by supplying tryptophan in the complete amino acid mixture.

The mechanism of polysome formation in response to amino acid supply is not explained by the experiments reported thus far. It is conceivable, however, from the observed increase in specific activity of RNA in the polysome fraction and from the morphological appearance of the liver cell nuclei during different phases of cell activity, that nuclear involvement may have to be considered. At the same time, the replenishment of large polyribosome components may be mediated in part within the cytoplasmic compartment.

I would like to thank Dr E. A. C. Follett and Miss M. Young of the Institute of Virology, Glasgow University, for their interest and efforts in producing the electron micrographs. The work was supported by US Public Health Service Fellowship Grant 5-F2-CA-28,000-02 from the National Cancer Institute.

\section{REFERENCES}

Benedetti, E. L., Bont, W. S. \& Bloemendal, H. (1966). Lab. Invest. 15, I96.

Campbell, P. N. (1966). The Structure and Function of Animal Cell Components. Oxford: Pergamon Press.

Caro, L. G. \& Palade, G. E. (I 964). 7. cell Biol. 20, 473.

Chen, M-L., Rogers, Q. R. \& Harper, A. E. (1962). F. Nutr. 76, 235.

Christensen, H. N. (1955). In Amino Acid Metabolism, p. 63. [W. D. McElroy \& B. Glass, editors.] Baltimore: Johns Hopkins Press.

Dawson, R. \& Holdsworth, E. S. (1962). Br. Y. Nutr. 16, 13.

Delhumeau, G., Velez Pratt, G. \& Gitler, C. (1962). F. Nutr. 77, 52.

Fleck, A. \& Begg, D. (1965). Biochim. biophys. Acta x08, 333.

Fleck, A., Shepherd, J. \& Munro, H. N. (I965). Science, N.Y. r5o, 628.

Hanking, B. M. \& Roberts, S. (1965). Nature, Lond. 207, 862.

Henriques, Q. B., Henriques, S. B. \& Neuberger, A. (1955). Biochem. F. 60, 409. 
Kipnis, D. M., Reiss, E. \& Helmreich, E. (196r). Biochim. biophys. Acta 4r, 5 r 9.

Lockwood, W. R. (1964). Anat. Rec. 150, 129.

Luft, J. H. (1961). F. biophys. biochem. Cytol. 9, 409.

Nasset, E. S. \& Ju, J. S. (196r). F. Nutr. 74, 46r.

Noll, H., Staehelin, T. \& Wettstein, F. O. (1963). Nature, Lond. x98, 632.

Shelton, E. \& Kuff, E. L. (1966). F. mol. Biol. 22, 23.

Twombly, J. \& Meyer, J. H. (I96I). $\mathcal{F}$, Nutr. 74, 453.

Villa-Trevino, S., Farber, E., Staehelin, T., Wettstein, F. O. \& Noll, H. (I964). F. biol. Chem. 239, 3826.

Watson, M. L. (1958). F. biophys. biochem. Cytol. 4, 727.

Webb, T. E., Blobel, G. \& Potter, V. R. (1964). Cancer Res. 24, 1229.

Wettstein, F. O., Staehelin, T. \& Noll, H. (1963). Nature, Lond. r97, 430.

Wunner, W. H., Bell, J. \& Munro, H. N. (I966). Biochem. F. 101, 417.

\section{EXPLANATION OF PLATES}

Plate 1

Details of a portion of a liver cell from a rat $2 \mathrm{~h}$ after feeding with a complete amino acid mixture. The morphologically distinct types of polyribosomes are seen as ribosomes attached (AR) to membrane of the endoplasmic reticulum and as spirals, rosettes and rows of free polysomes (FP) in the cytoplasmic matrix. Part of the nucleus $(\mathrm{N})$ is seen at the top of the photograph, and mitochondria $(\mathrm{M})$ are of normal appearance. The sample was fixed with osmium tetroxide, embedded in Epon and poststained with uranyl acetate and lead hydroxide.

PLATE 2

(a) Enlarged area of the cytoplasmic matrix in a liver cell from a rat $2 \mathrm{~h}$ after feeding with a complete amino acid mixture. Ribosomes are seen attached to the lamellar cisternae of the endoplasmic reticulum arranged roughly in parallel.

(b) Enlarged area of free polysomes partially surrounded by mitochondria in a liver cell from a rat $2 \mathrm{~h}$ after feeding with a complete amino acid mixture is well organized with numerous spirals, circles and rows of ribosomes unattached to membrane. A portion of the nucleus is seen at the right of the photograph.

PLATE 3

(a) Portion of a liver cell from a rat $2 \mathrm{~h}$ after feeding with an amino acid mixture lacking tryptophan. The degree of cytoplasmic organization of the free polysome system and continuity of lamellar cisternae of endoplasmic reticulum is reduced. The ribosome-studded membranes of the endoplasmic reticulum appear to be fragmented and considerably expanded into membrane-limited vacuoles. The sample was fixed and stained as described in Pl. I.

(b) Enlarged area of the cytoplasmic matrix partially surrounded by mitochondria in a liver cell from a rat $2 \mathrm{~h}$ after feeding with an amino acid mixture lacking tryptophan contains fewer well organized spirals of free polysomes and more free ribosomes and small clusters of ribosomes.

(c) Enlarged area of the cytoplasmic matrix in a liver cell from a rat $2 \mathrm{~h}$ after feeding with an amino acid mixture lacking tryptophan contains few well organized free polysomes and many membranelimited vacuoles.

\section{PLATE 4}

(a) Portion of a liver cell from a rat $7 \mathrm{~h}$ after feeding with an amino acid mixture lacking tryptophan. The ribosome-studded lamellar cisternae of the endoplasmic reticulum is well organized in long channels. The nucleus is heterogeneously stained with considerable nucleoprotein at the periphery. The sample was fixed and stained as described in PI. I.

(b) Enlarged area of the cytoplasmic matrix in a liver cell from a rat $7 \mathrm{~h}$ after feeding with the tryptophanfree amino acid mixture shows an organization of free polysomes.

(c) Enlarged area of a liver cell from a rat $7 \mathrm{~h}$ after feeding with a complete amino acid mixture has an organization of the free polysome system that is comparable to that shown in $\mathrm{Pl}, 4 B$. The sample was fixed and stained as described in Pl. I. 


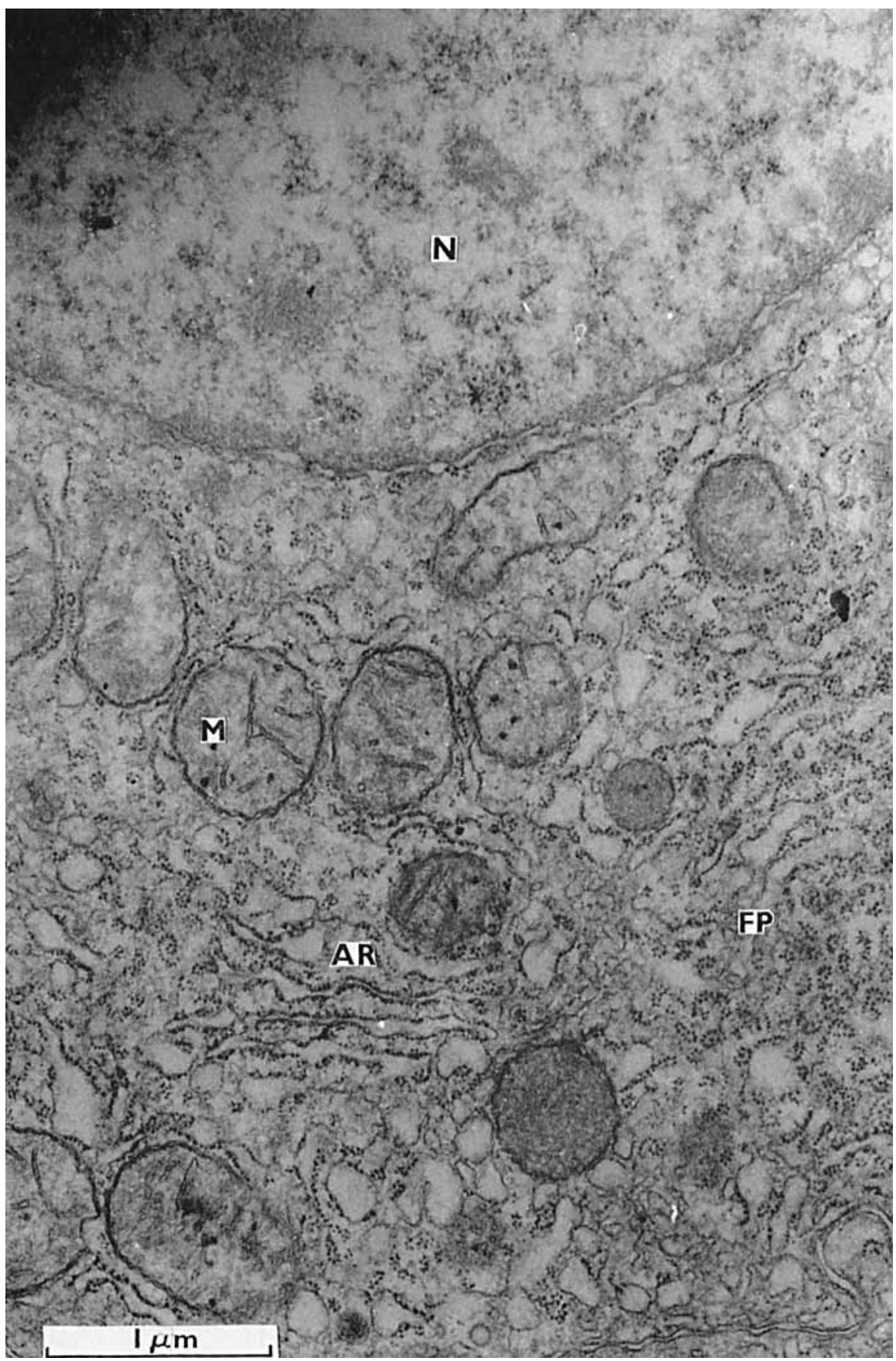




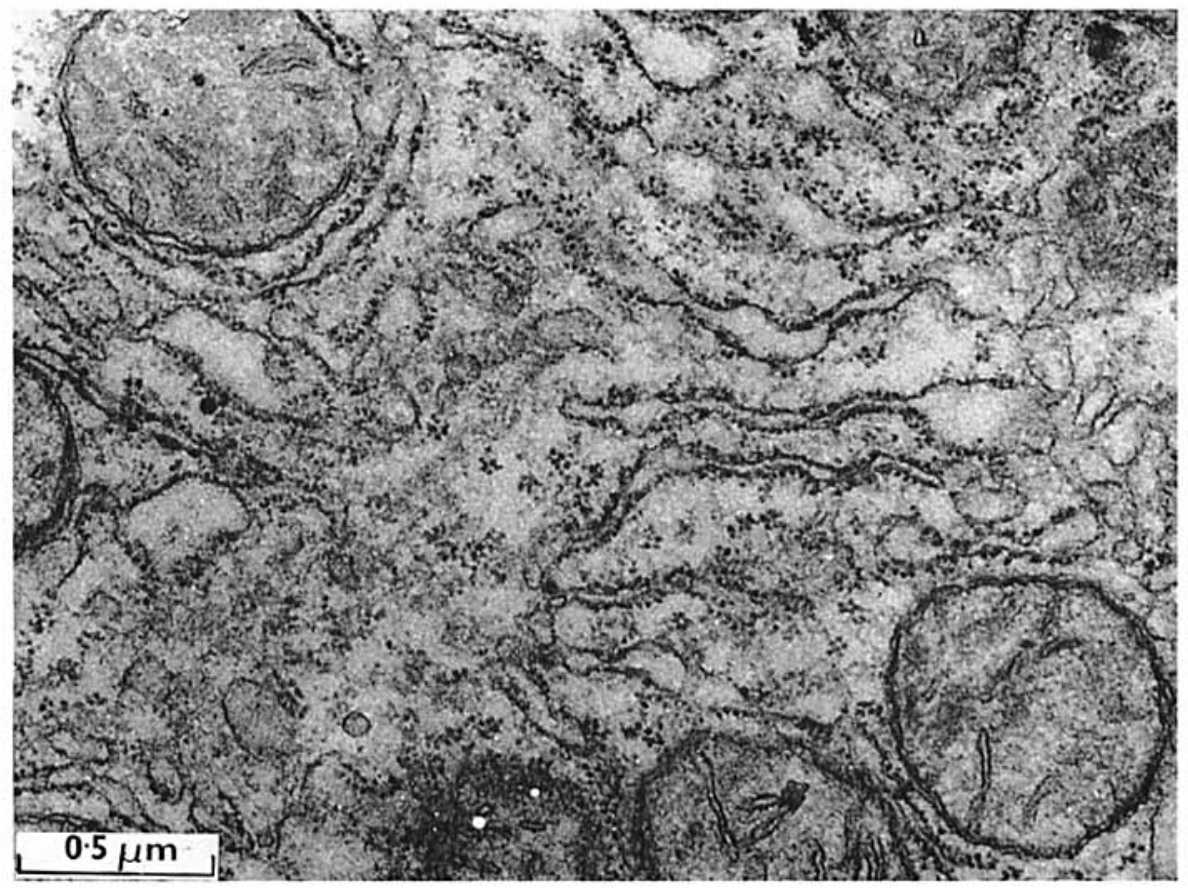

(a)

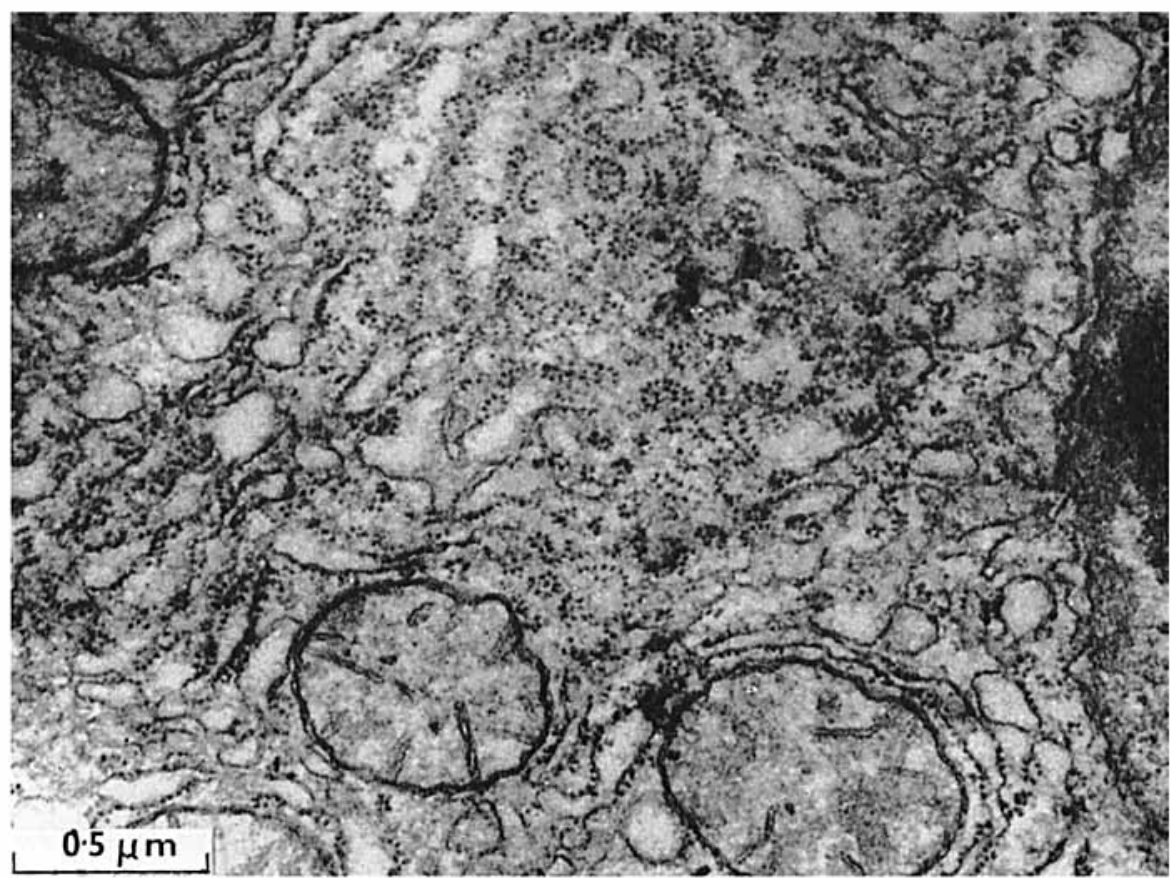

(b)

W. H. WUNNER 


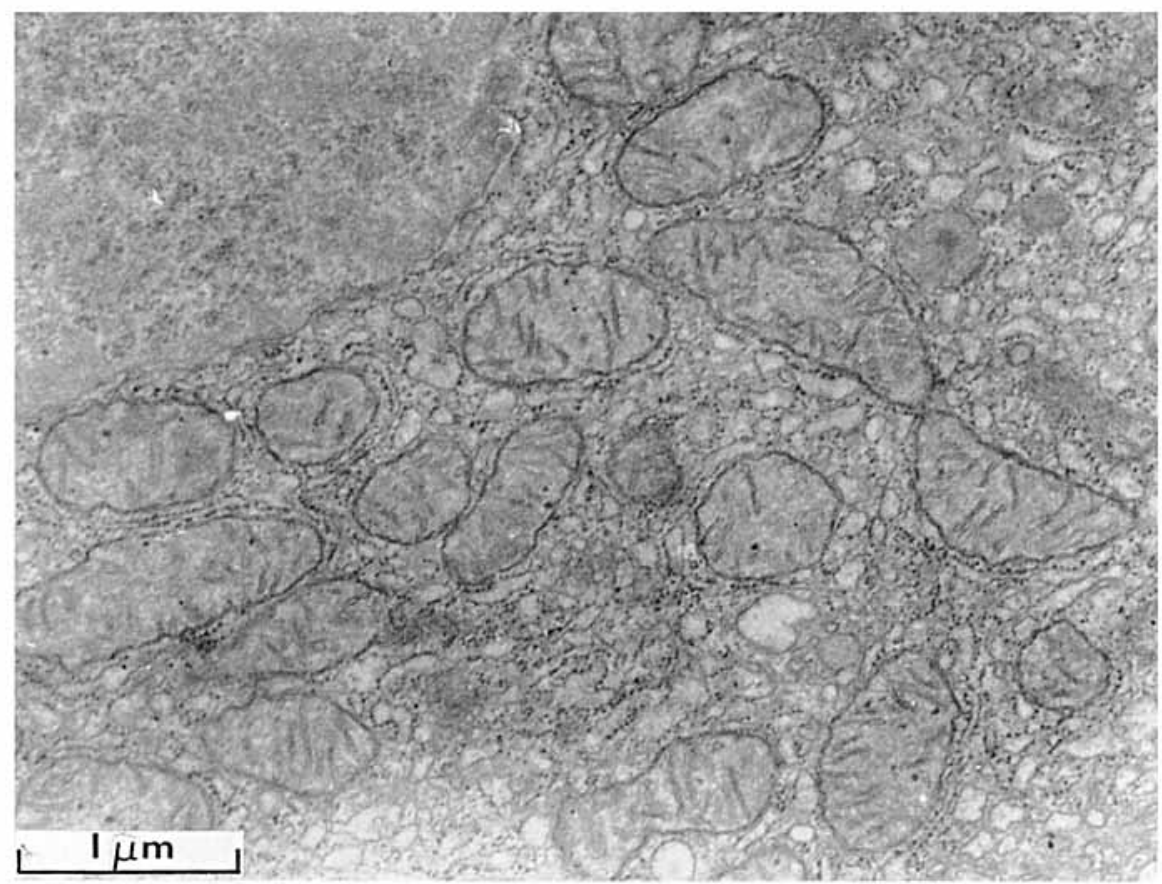

(a)

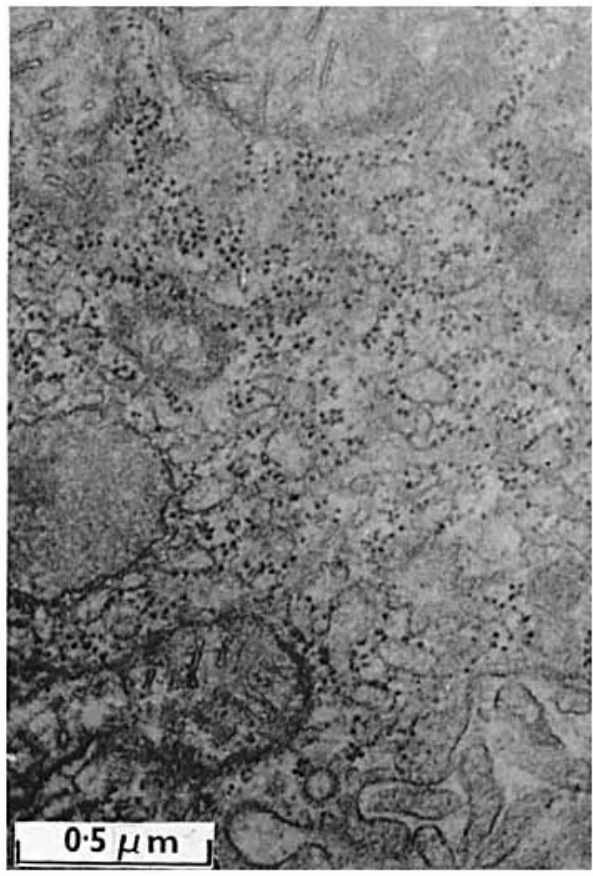

(b)

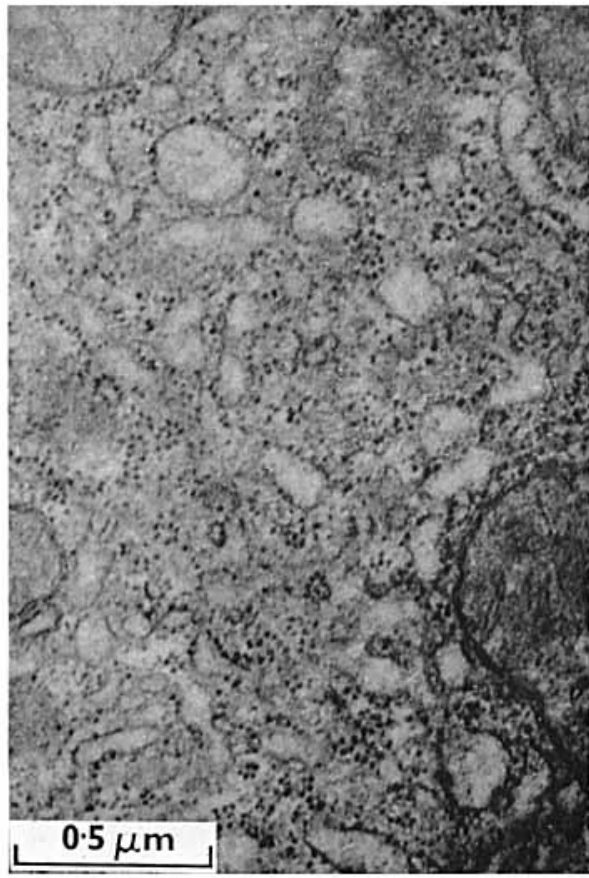

(c)

W. H. WUNNER 


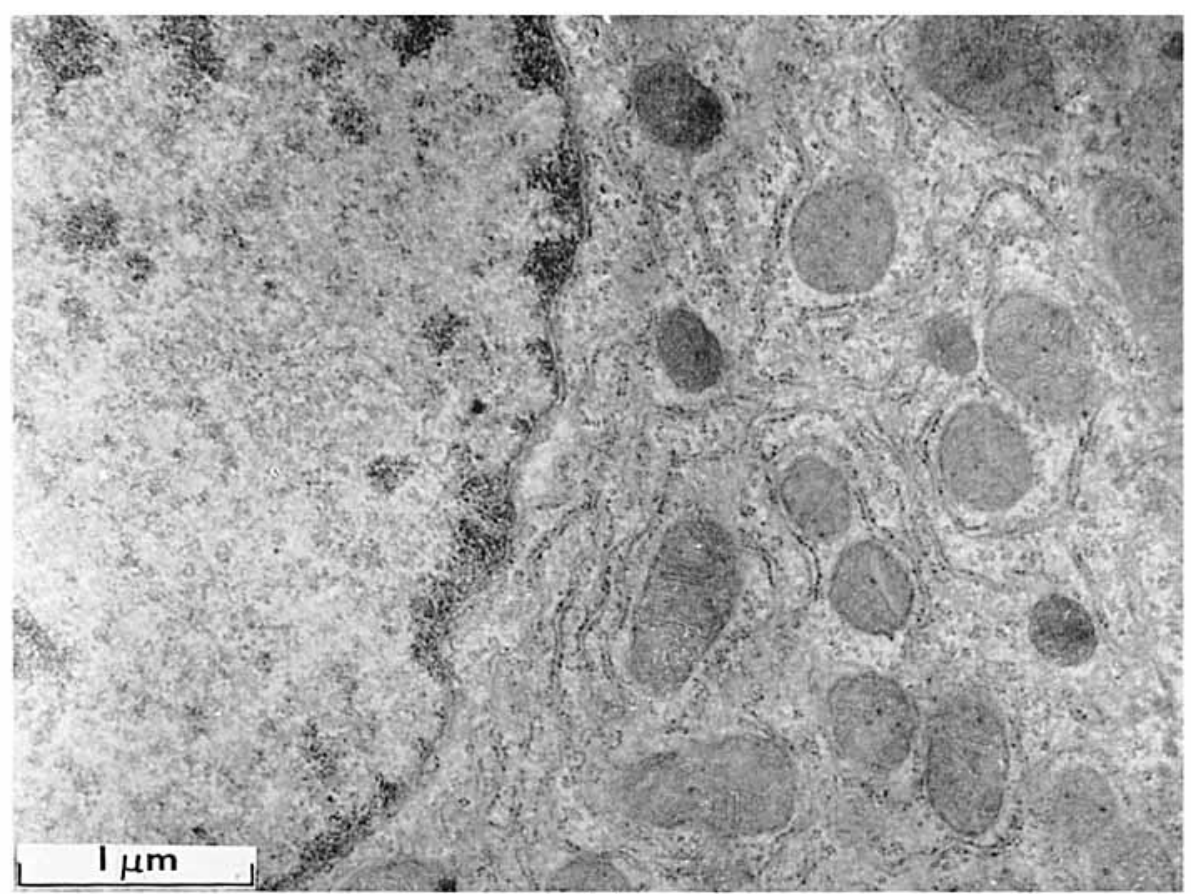

(a)

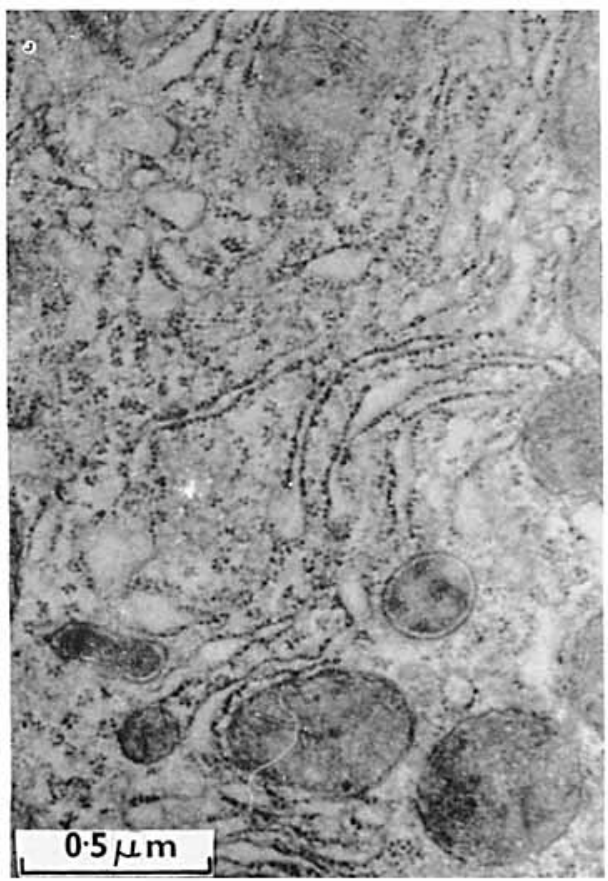

(b)

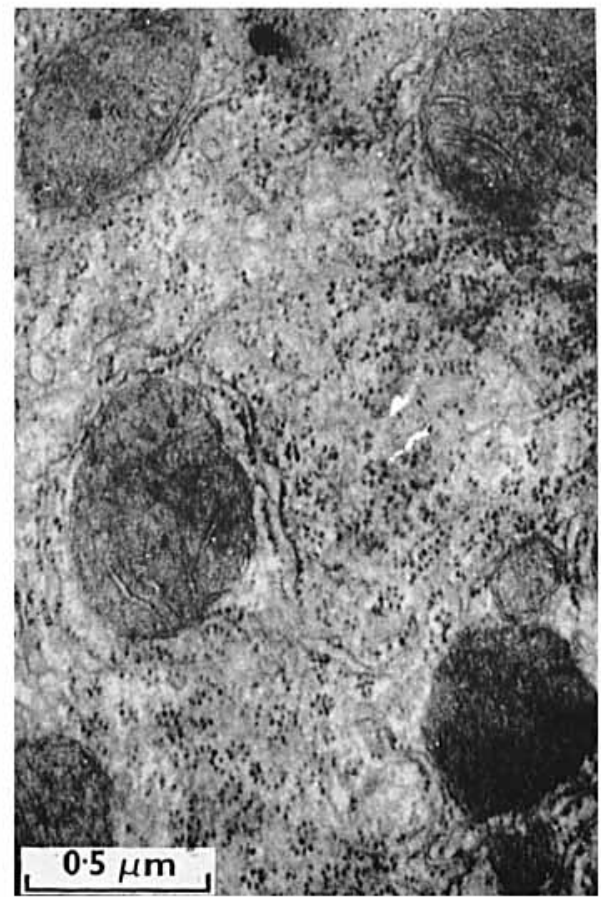

(c)

W. H. WUNNER 


\title{
Adaptation to overfeeding in man
}

\section{By J. A. Strong, Department of Medicine, Western General Hospital and R. PASSMORE, Department of Physiology, University of Edinburgh}

A short account of work carried out by the authors was given. A full presentation will be published (Strong, Shirling \& Passmore, I967). The summary of this paper is as follows:

Food which provided from 2960 to $7880 \mathrm{kcal}$ in excess of requirements was eaten by sixteen subjects, each for a period of 4 days.

The proportion of the nutrients lost in the faeces was not increased during overfeeding.

The metabolic rates were in no case increased by an amount equivalent to more than $15 \%$ of the excess calories. The increase could be attributed to the specific dynamic effect of the extra dietary protein.

The gains in weight ranged from 370 to $5460 \mathrm{~g} / 4$ days and the calorie equivalent of the weight gained varied from $\mathrm{I} \cdot \mathrm{I}$ to $10.0 \mathrm{kcal} / \mathrm{g}$. These variations can be attributed to variations in the amount of water retained.

Analysis of their respiratory exchanges suggests that most subjects stored from 400 to $1500 \mathrm{~g}$ carbohydrate in the tissues, possibly in the form of muscle glycogen.

REFERENCE

Strong, J. A., Shirling, D. \& Passmore, R. (1967). Br. F. Nutr. 2r, 909.

\section{The effect of changes in feeding patterns on the performance of pigs}

\author{
By R. BRAUDE, National Institute for Research in Dairying, \\ Shinfield, Reading
}

In feeding livestock, three basic questions must be considered: what, how much, and how to feed? The qualitative and quantitative aspects have been studied by many and information has accumulated which, though by no means complete, permits formulation of standards, requirements and allowances. It is only fairly recently that it has become clear that the problem of 'How should one feed' is of basic importance in nutrition, and that understanding of it may help to resolve some of the present controversies about feeding standards and requirements. The problem of how to feed is affected by so many factors that it is virtually impossible to arrive at any hard and fast rules or to make valid general recommendations. All one can do in a brief review is to draw attention to the many aspects of the problem and to some of its implications.

In Table I I have listed under three headings, some of the factors which may influence the pattern of feeding: those connected with the animal, those connected with the feed, and those connected with the management. The list is by no means complete, but it points to the complexity of the problem. It becomes even more 